\title{
Chapter 6 \\ Moving Towards a Better Understanding of Socioeconomic Inequalities in Preventive Health Care Use: A Life Course Perspective
}

\author{
Sarah Missinne
}

\section{Introduction}

Despite the abundance of empirical studies that have targeted a whole range of social groups and (preventive) health services, little remains understood about the underlying mechanisms that drive persistent socioeconomic inequalities in preventive health care use. Recently, cultural health capital and health lifestyles have been discussed theoretically with regard to their roles in preventive health care inequalities. Given substantial analogies, I explore in this chapter how our understanding of cultural health capital and preventive health care inequalities can be advanced by applying the five theoretical principles of the life course perspective as described by Elder and colleagues (2003). The objective is to set out a framework that can be applied to different forms of preventive health care. However, I use the example of mammography screening, as this preventive health habit has been the focus of my empirical research. There are several reasons for this choice. First, breast cancer constitutes a very important public health issue, as it is the most frequently diagnosed form of cancer among European women (Ferlay et al. 2010) and the leading cause of female death from cancer (Ferlay et al. 2013; Jemal 2011). Mammography screening is the only evidence-based method for detecting breast cancer at an early stage (Youlden et al. 2012), and has improved survival rates by 19 to $32 \%$ in several European countries for women in the age range 50 to 69 (Hakama et al. 2008). Socioeconomic inequalities have also been reported with regard to mammography screening (e.g. Duport and Ancelle-Park 2006; Jusot et al. 2011).

\footnotetext{
S. Missinne $(\bowtie)$

Department of Sociology, Ghent University, St. Pietersnieuwstraat 33, Ghent 9000, Belgium e-mail: Sarah.Missinne@UGent.be

(C) The Author(s) 2015 
The second reason for choosing mammography screening relates to data availability. Information is available about the year in which women commenced regular mammography screening. Unfortunately, information on the timeliness is rare in the field of preventive health care despite the fact that the notion of timing is also a vital aspect of preventive health habits, as is outlined below. This duration data enables us to illustrate the potential of all five life course principles for preventive health care research ${ }^{1}$ by means of event history analysis. This statistical technique is commonly used in life course research, as the concept of transition is central to both the theoretical perspective and the statistical modeling of event histories (Wu 2003).

The chapter is structured as follows: first, I outline how preventive health care inequalities have been approached traditionally, before focusing in detail on cultural health capital theory and health lifestyle theory. Each of the five principles of the life course perspective and their potential application and similarities with preventive health care research are elaborated upon separately, although there is unavoidably some overlap. Each time, I refer to previous empirical work to illustrate the empirical application of a particular principle using the example of mammography screening.

\section{Theoretical Models on Preventive Health Care Inequalities}

\section{Traditional Approaches to Preventive Health Care Inequalities}

To assess socioeconomic inequalities in preventive health care use, the needadjusted approach based on Andersen's heuristic model of health service use (Andersen et al. 1970; revised form: Andersen 1995) is generally relied upon. Researchers define and adjust for indicators of 'need' and subsequently assess whether socioeconomic inequalities in health care use persist. Inequity arises, for example, if individuals in higher socioeconomic groups are more likely to use, or are using, a greater quantity of health services - after controlling for their level of ill-health - compared with that of lower socioeconomic groups (van Doorslaer et al. 2006).

In addition to the need-adjusted approach of Andersen (1970, 1995), socioeconomic differences in preventive health care use have traditionally been explained by theoretical models of health behavior, such as the widely-used health belief model (Becker and Maiman 1975) and the theory of reasoned action (Fishbein and Ajzen 1975). Importantly, these models highlight the role of beliefs (about perceived risks,

\footnotetext{
${ }^{1}$ The other side of the coin is that the effectiveness of mammography screening continues to be a widely-debated prevention strategy (Gotzsche and Nielsen 2009), despite general guidelines by the WHO (2013) and the European Union. Although this renders the discussion somewhat more complex on several points, it does not hinder us in our aim to set up a new framework for preventive health care research.
} 
severity, efficacy of personal action, benefits, and costs) in preventive health care use, and contend that use is not determined by financial means alone, as is often assumed when adopting a need-adjusted approach (Rajaram and Rashidi 1998). However, these agency-oriented paradigms lack an understanding of how beliefs are socially and culturally structured (Blane 2008; Frohlich et al. 2001; Rajaram and Rashidi 1998) and how they are acquired over the course of an individual's life. In twenty-first century medical sociology, there is now a growing awareness that understanding the true social rooting of health and illness requires a shift from the dominant agency-oriented paradigms towards a more neo-structural perspective (Cockerham 2005, 2007).

\section{Cultural (Health) Capital Theory}

Recent theoretical developments have aimed to underline the structural dimension of health and health care habits. A central element is the conceptualization of social position. Scholars have argued that in current post-industrial societies, stratification is not driven by social class alone (Clark and Lipset 2001). As a result of better labor conditions, increasing wages, and disposable time, consumption patterns have gained importance (Bogenhold 2001). Therefore, the explicit inclusion of cultural capital in explanatory approaches to social inequality in health and health behavior has been advocated, rather than deducing it from general measurements of socioeconomic status (SES), such as social class and income (Abel 2008; Abel and Frohlich 2012; Shim 2010). Bourdieu (1986) described how inequality could be reproduced by the interplay of three different forms of capital: economic, social, and cultural. He further identified three different forms of cultural capital: objectivized (e.g. books, artefacts, paintings), institutionalized (e.g. education, job title) and the embodied state incorporating mind and body (e.g. values, skills, knowledge).

When applying Bourdieu's (1986) general notion of cultural capital to health and health care research, what is termed cultural health capital can be defined as comprising "all culture-based resources that are available to people for acting in favour of their health. In its incorporated form it comprises health-related values, behavioural norms, knowledge and operational skills" (Abel 2008, p. 2). This form of cultural capital becomes directly relevant to health through the adoption of healthy lifestyles, such as engaging in preventive care (Abel 2008; Abel and Frohlich 2012; Phelan et al. 2004; Shim 2010).

Analogous to life course research, a longer view of an individual's life is taken when elaborating on how cultural health capital develops. It has been argued that the health-relevant knowledge and skills used to lead healthy lives start accumulating in childhood and this proceeds over the life course through repeated contacts with health care providers and lifelong socialization (Abel and Frohlich 2012; Mirowsky and Ross 2003; Shim 2010). Cultural health capital theory highlights that people's behavioral options and preferences are structurally constrained and unequally distributed between social groups (Abel 2008). 


\section{Health Lifestyle Theory}

In the same theoretical tradition, Cockerham $(2005,2007)$ developed the 'health lifestyle theory' to underline the structural dimensions of health lifestyles. Starting from Weber's lifestyle concept (Weber [1922] 1978), Cockerham described health lifestyles as "collective patterns of health-related behaviour based on choices from options available to people according to their life chances" (Cockerham 2000, p. 165). Health lifestyles are largely shared by individuals close to one another in a social space, and whose similar opportunities in terms of life chances give rise to a shared general habitus as elaborated by Bourdieu. In La Distinction (1984), he outlined how this dialectic interplay between life choices and life chances gives rise to a set of lifestyle dispositions, which make up the habitus of individuals. Members of the same social class are more likely to share the same general habitus, because they internalize the same life chances. Hence, choices of health lifestyles are not uncoordinated, but are largely shared by social class members (Cockerham 2005, 2007) and are likely to be transmitted intergenerationally (Wickrama et al. 1999). Bourdieu's notion of habitus (1984) entails that "health-related behaviour can be seen as a largely routinized feature of everyday life which is guided by a practical or implicit logic" (Williams 1995, p. 583). Therefore, not every use of available resources, including cultural health capital, is as conscious as traditional models of health behavior assume (Abel and Frohlich 2012; Shim 2010).

Cockerham (2007) highlighted that notwithstanding their own complexities, health practices comprise an overall pattern, accordingly the regular take-up of preventive mammography screening can be viewed as an expression of a health lifestyle that started to develop during childhood. There is also empirical support for a general behavioral orientation towards a health lifestyle (Donovan et al. 1993).

\section{Preventive Health Care Inequalities Along the Five Principles of the Life Course Perspective}

\section{Principle 1: Life-Span Development}

The life course perspective is distinctive for its extended time frame and its focus on evolving dynamics that begin in early childhood (Elder et al. 2003). A key issue that is addressed is the sociogenesis of inequality between people over the life course (Schafer et al. 2011). Early advantage or disadvantage can set in motion a series of cascading socioeconomic and lifestyle events that have consequences across different domains in later life, such as education (Gamoran and Mare 1989) and work (Gangl 2004). More recently, the life course perspective has also been introduced in social epidemiology by Blane (1999), Kuh and colleagues (2003), and Halfon and Hochstein (2002). Studies have already revealed that early or midlife 
factors, such as childhood socioeconomic conditions and health, have long-term influences on adult health and mortality (Due et al. 2011; Hayward and Gorman 2004), and healthy ageing (Brandt et al. 2011). However, the role of the life course perspective in terms of preventive health care use still needs to be assessed.

Cultural health capital theorists have implicitly adopted the idea of life-span development. Yet, the way in which cultural health capital is acquired and how it evolves over time remain unexplored (Shim 2010). We are in the dark regarding whether and which specific life stages or experiences are crucial in the development of cultural health capital or health lifestyles (Singh-Manoux and Marmot 2005). Pioneering empirical studies on cultural health capital have been conducted (e.g. Dubbin et al. 2013). However, the developmental dimension of cultural health capital has not yet received much attention.

Childhood socioeconomic conditions can shape the development of healthrelated behaviors (Kuh et al. 2004) when parents transfer skills and knowledge to their children (Abel and Frohlich 2012; Singh-Manoux and Marmot 2005). In addition to setting an example by buying food, (alcoholic) beverages, engaging in sports, taking their children for regular dental check-ups, etc., the beliefs supporting parents' own health behavior are transmitted unintentionally or via explicit teaching efforts (Lau et al. 1990; Tinsley et al. 2002).

The SHARELIFE ${ }^{2}$ data enables the initial empirical testing of cultural health capital theory by including several unique measurements (see Missinne et al. 2014 for methodological details). The main question posed here is whether childhood is a decisive period in the development of preventive health behavior. Empirically, it is assessed whether cultural health capital in childhood, as approximated by childhood preventive behavior, predicts the take-up of mammography screening many years later in life. Figure 6.1 indeed shows that women who went to the dentist regularly for preventive check-ups during childhood are more likely, at every age, to take-up regular mammography screenings. The log-rank test confirms that this bivariate association is significant $(\mathrm{p}<0.001)$. To what extent is this association attributable to a more prosperous socioeconomic situation in childhood? The multivariate models ${ }^{3}$ demonstrate that engaging in preventive health behavior during childhood is associated with an increased hazard of mammography screening of $45 \%$, regardless of traditional socioeconomic factors of childhood (the ISCO88 of the main breadwinner's job and the number of books in the household). This early-life advantage only decreases slightly $(15.6 \%=0.38-0.45 / 0.45)$ when the adulthood socioeconomic position (wealth and education) is additionally taken into account. As suggested by the full-path dependence model (DiPrete and Eirich

\footnotetext{
${ }^{2}$ The Survey of Health, Ageing and Retirement (SHARE, www.share-project.org) is a multidisciplinary and cross-national panel database on health, socioeconomic status, and social and family networks. The third wave which provides retrospective life course information, is used (SHARELIFE)

${ }^{3}$ The models all account for cohort and period effects as well as the age-eligibility for the Belgian national screening program.
} 

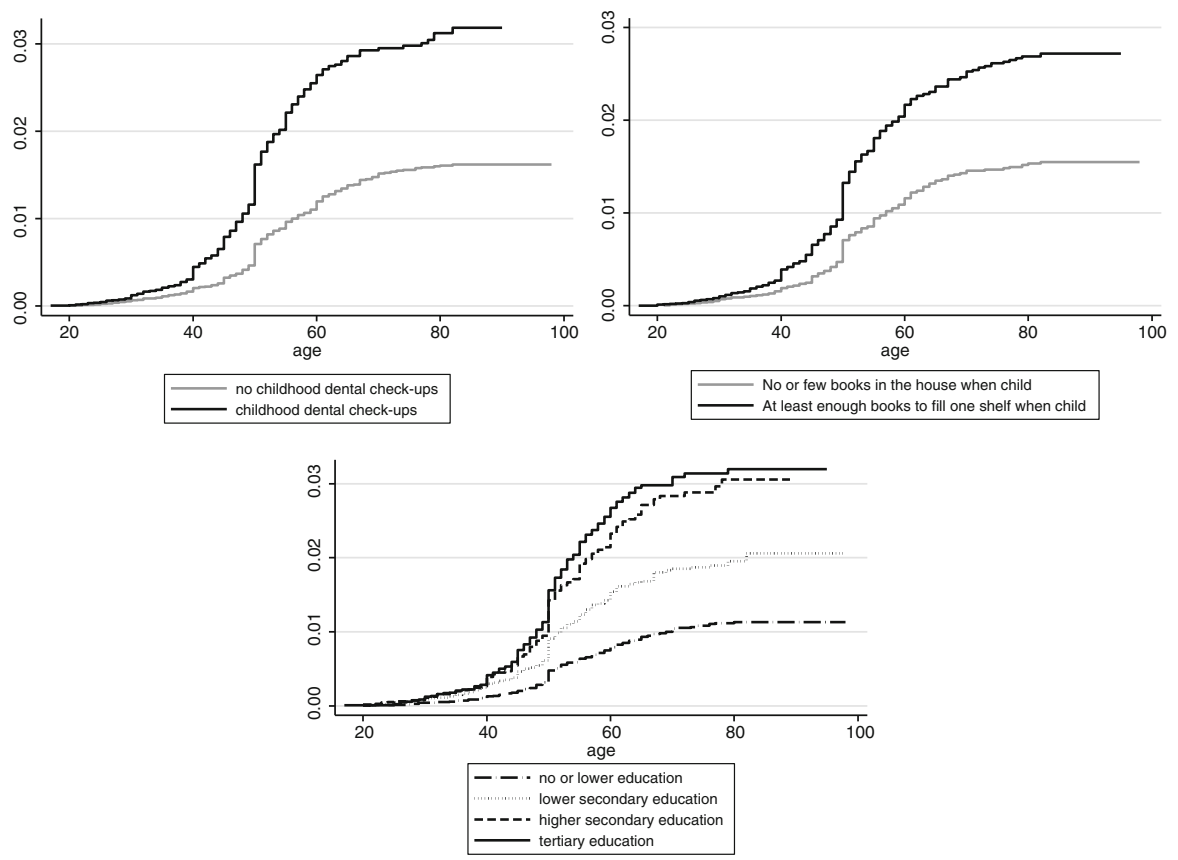

Fig. 6.1 Cumulative hazard functions for starting mammography screening in Belgium, by dental check-ups and cultural capital during childhood, and education (Nelson-Aalen estimates)

2006), childhood conditions seem to play a substantial role in engagement in preventive health behavior during later life and in the accumulation of cultural health capital.

Other forms of cultural capital have become increasingly important within the framework of cultural health capital theory and health lifestyle theory. A measurement of cultural capital in the childhood household (number of books) and a traditional measurement in adulthood (education) could be included. The former is an indicator of objectivized cultural capital in Bourdieu's framework (1986) and is considered to be a powerful proxy for the educational, social, and economic background in early life (Schutz et al. 2008). Figure 6.1 illustrates its significant association with mammography screening $(\mathrm{p}<0.001)$. However, the advantage of cultural capital during childhood (number of books) does not persist after controlling for adulthood social position in the multivariate models. Education is considered as a form of institutionalized cultural capital. It is a distinct aspect of socioeconomic status, as it involves essential problem-solving skills and learned effectiveness, which enable people to control their lives, including health (Mirowsky and Ross 2003). Its decisive role for preventive health habits, such as mammography screening, is well-established (Stirbu et al. 2007). The significant association with education $(\mathrm{p}<0.001$, see Fig. 6.1) remains crucial, with an increased hazard for mammography screening for tertiary-educated women compared with their lesser- 
educated counterparts. The effects are even stronger than those for wealth, which suggests that individual competences have indeed become increasingly important.

\section{Principle 2: Timing of Outcomes}

Life course researchers are particularly interested in the "social patterns in the timing, duration, spacing and order of events and roles" (Elder and Rockwell 1979, p. 2). Attention is paid to how certain transitions or events can produce different effects depending on their timing within the life course (George 1993). For example, the consequences of the Great Depression were different for older and younger children (Elder 1974). In addition, in life course epidemiology the notions of timing and duration are central to the three main models for the association between early life circumstances and later life: the latency, pathway, and accumulation models (Graham 2002).

By contrast, the temporal dimension of preventive behaviors has been generally ignored in both empirical research (Spadea et al. 2010) and medical sociological theory (Missinne et al. 2014). This is somewhat unfortunate, as the effectiveness of care depends upon a timely initiation of preventive care or check-ups and upon its regular use. As a result of the focus on rates of illness-related health care use in the Andersen's framework (1983) and the dominant use of cross-sectional study designs, questions about (preventive) health care use are formulated along the lines of: "during the last xx months/years, have you consulted a specialist/GP/dentist/had a mammogram ?". This design and this question wording render it impossible to scrutinize both the timeliness and regularity of preventive behavior. To capture a regular pattern of care, the perception of a 'usual source of care' (e.g. "is there a particular doctor you usually go to when ill, or for advice about health?") is also often used. However, this type of measurement also fails to adequately capture periodic behavior and even the preventive nature of a visit (Newman and Gift 1992).

Timely detection of breast cancer is crucial given that the stage of illness (or tumor size) at diagnosis is strongly linked to survival (Elmore et al. 2005). Therefore, the Council of the European Union recommends that screening programs target women aged 50 to 69 years of age (von Karsa et al. 2008), who are at the highest risk of breast cancer. Age is generally regarded as a control or a confounding variable, or is used as a proxy for 'need' for general health care use (Van der Heyden et al. 2003), preventive health care use (e.g. Jusot et al. 2011), and for mammography screening (e.g. Duport and Ancelle-Park 2006; Wübker 2012). In addition, the regularity of preventive habits is recommended. For example, a twoyear interval is recommended for mammography screening (European Commission 2003), six months for dental check-ups (Riley et al. 2013) and targeted groups should be given a flu vaccination every year.

In the discussion concerning the social gradient, the temporal dimension should also be included. It is possible that socioeconomic inequalities are partly manifested in both the regularity and the timeliness of preventive health care use, in addition 
to the probability of ever engaging in it (Missinne et al. 2014). For example, health insurance data has shown that in Belgium, the dropout rate for two-yearly mammography screening is higher among women who benefit from preferential reimbursement (Fabri et al. 2010). Higher-educated groups might be more future oriented and more willing to commit to a long-term goal, such as prevention (Mirowsky and Ross 2003; Wübker 2012). Accordingly, it is possible that cultural health capital includes knowledge or competencies that enable the timely and regular use of preventive health care.

The way the SHARELIFE investigates mammography screening includes both notions of temporality and regularity. The question, "In which year did you start having mammograms regularly?" was given to all women who answered yes to the question "Have you ever had mammograms regularly over the course of several years?" This retrospective information allows us to gain insight into two important questions relating to the timeliness of mammography screening. The first question relates to the age differences that are often reported for mammography screening. Empirical studies generally report lower engagement in screening among older women (Wübker 2012), but confusion remains substantial (Jepson et al. 2000). The dominant question wording renders it impossible to know whether age differences reflect 'true' age effects or whether they act as proxies for period effects. ${ }^{4}$ The latter is very probable, as knowledge about - and policy initiatives concerning breast cancer and mammography screening have changed considerably in Europe during recent decades (Fisher et al. 2008). To this end, an explorative approach has been followed. Five birth cohorts from 1910 to after 1949 in ten-year intervals were constructed and the Kaplan-Meier graphs were tabulated for the 13 European countries that took part in the SHARELIFE (see Fig. 6.2 for three examples; for details see Missinne and Bracke 2014). The results do indeed suggest substantial period effects. In all countries, earlier birth cohorts overall engage less in screening. Figure 6.2 show that the hazard function for each earlier birth cohort is lower at all ages, except for Sweden. Very similar age trajectories can be observed for each cohort, suggesting no 'true' age effects. The cross-national comparative approach aids in framing these period effects within the context of national screening policies, which have already been empirically linked to the large country-differences in mammography screening (Wübker 2014), illustrated in Fig. 6.4. I will return to this point when elaborating on principle 4 . In addition, country-specific deviations can be related to features of national screening policies, again suggesting strong period effects. For example, the coinciding hazards of the two most recent cohorts, as well as an additional increase at the age of 40 , can be traced back to the early implementation of a national screening program in 1986, which targets women from the age of 40 in $65 \%$ of Swedish counties. In Belgium, women are invited to participate from the age of 50 . In Greece, the absence of a sudden increase indeed

\footnotetext{
${ }^{4}$ Glenn (1976) called statistical attempts to separate age, period and, cohort effects "a futile quest" (for an elaboration, see Glenn 2003). Therefore, I have followed his suggestion to use a more informal approach.
} 



Fig. 6.2 Cumulative hazard function for mammography screening initiation in Sweden, Belgium, and Greece per 10-year birth cohort (Nelson-Aalen estimates)

reflects the absence of a national program (for an overview of screening policies, see von Karsa et al. 2008).

Next, the hypothesis that socioeconomic inequalities could also be manifested in the timeliness of the take-up of mammography screening was tested. Returning to Fig. 6.1 and focusing on the specific age trajectories, an increase of screening around the recommended age of 50 is notable for all social groups. These age trajectories do not differ according to socioeconomic indicators for either childhood (Fig. 6.1) or adulthood (Fig. 6.1). Accordingly, in line with what studies have traditionally assumed, socioeconomic inequalities seem to be manifested in Belgium as a lower probability of ever having a mammogram, rather than in the late commencement of screening. This finding should be interpreted in the light of the relatively small age range for which screening is recommended. The discussion about timeliness should therefore not be closed. For example, for preventive services that begin far more early in life, such as dental check-ups, timeliness might reveal clearer socioeconomic inequalities in preventive health care.

\section{Principle 3: Agency Versus Structure Debate}

The principle of agency stresses that individuals are not passive recipients. Encapsulated in life course research is the question of how the interplay between individual 
action and the social structure shapes the lives of individuals. Individuals act and make choices within the opportunities and constraints of their world (Elder et al. 2003). For example, Elder described how parents and children successfully adapted to the difficult circumstances during the Great Depression (Elder 1974, 1998).

In the introductory section of this chapter, I already touched on the structureagency debate, which has also received considerable research attention in medical sociology (Abel and Frohlich 2012), most directly when studying health inequalities (Cockerham 2005). Recently, medical sociologists have endeavored to theorize the relative importance of agency and structure for health and health lifestyles (Williams 1995; Cockerham 2005, 2007; Abel and Frohlich 2012). It is acknowledged that "counterposing agency with structure is a misplaced and false dichotomy" (Dannefer and Daub 2009, p. 20). Instead, they can be recursive (Frohlich et al. 2001) and the question is the extent to which either one is dominant in a particular situation (Cockerham 2007). Cultural health capital theory focuses on the specific situation of health care interactions. In this way, the broader macrostructural level of the unequal distribution of resources is linked to micro-level practices (Abel 2008; Abel and Frohlich 2012). Shim (2010) highlighted that individuals are not passive recipients of cultural health capital strongly tied to social stratification.

Another way to gain insight into the structure-agency debate is by focusing on the different socialization contexts socially-mobile individuals are confronted with over their life course. Each social position largely determines the 'life chances' of individuals at that time and these positions constitute the structuring forces of 'life choices' (agency) on health lifestyles (Cockerham 2005). The weight that Bourdieu attributed to childhood experiences in the formation of the habitus, has often been critiqued (Daenekindt and Roose 2013). Social mobility research parallels this idea by addressing the multiple contexts of socialization, each with its own health-related practices. Socialization continues into adulthood, when individuals are confronted with new experiences (Ryder 1965) and other significant network members become important for health behaviors (Christakis and Fowler 2007), for example marital partners (see the principle of linked lives). Social mobility research can gain insights into the development of health lifestyles by scrutinizing the relative impact of the social position in childhood versus the prevailing social position.

Using the example of mammography screening has two advantages when studying the health behavior of socially-mobile individuals. First, it is only recommended from the age of 50 onwards (WHO 2013), when social mobility processes are likely to have been actualized. Therefore, this type of health behavior is not likely to affect the course of social mobility. In most studies, such a process of reversed causality cannot be ruled out and hampers causal interpretations of the effect of social mobility (Claussen et al. 2005). Second, it is very unlikely that mammography screening is related to the event and the accompanying stress of social mobility itself, as has been suggested for health-compromising behaviors such as alcohol use or dietary patterns (Karvonen et al. 1999). 
Diagonal Reference Models (DRMs) were designed in particular to study the effects of social mobility and enable estimation of the relative impact of the social position of origin and the social position of destination. The screening behavior of socially-immobile individuals is taken as the reference points, as they represent the core of each social stratum. Therefore, their health-related behavior is considered characteristic for that social position. Consequently, the health behavior of sociallymobile individuals is modeled as a function of the characteristic behavior of immobile individuals from the social position of origin and of destination (for an outline of the empirical strategy, see Daenekindt and Roose 2013; for examples in health research, see Monden and de Graaf 2012). These models were applied to the Belgian sample of the SHARELIFE to test three hypotheses: (i) health behavior is, in line with Bourdieu, predominantly shaped by the primary socialization context: the social position of origin; (ii) the health behavior of socially mobile individuals is predominantly associated with the social position of destination; and (iii) the maximization hypothesis considers whether the experience of upward social mobility differs from that of downward social mobility. The results showed that the take-up of mammography screening by both upwardly and downwardly mobile individuals reflects the patterns of the women in their prevailing social position. Therefore, empirical support is only found for the second hypothesis. This points to the situational nature of mammography screening, which is also highlighted in the empirical example outlined in the next principle. However, it does not necessarily contradict our findings that childhood socioeconomic conditions are crucial in the development of cultural health capital (principle 1). The data limited us to considering only occupational mobility, which is regrettable given that the role of cultural capital in particular, such as education, has been seen as increasingly important.

\section{Principle 4: Linked Lives}

With its principle of linked lives, the life course perspective highlights that individual lives are lived interdependently in a network of shared relationships (Elder et al. 2003). Because experiences are shared, the relevance of various social events and transitions is widened (Heinz and Kruger 2001). These interpersonal experiences are also located within a specific historical time and place that can impact upon these micro-level settings (Elder et al. 2003).

Research on preventive health care and health care in general has focused too much on the individual in isolation. Andersen's (1970, 1995) heuristic model, focuses on how individual need, socioeconomic and demographic characteristics, and individual health beliefs are related to health services use. However, seeking professional care is often not the result of an individual decision, but of an interactive process (Pescosolido 1992). Recently, Umberson and colleagues (2010) drew explicitly on the life course perspective to provide a theoretical framework 
to unfold the mechanisms underlying the relationship between social ties and health behavior, including preventive health care use and treatment attendance. Predominantly, the focus is on the presumed beneficial effect of marriage. Healthrelated social control theories propose that partners try to influence and regulate each other's health behavior in order to keep their partners healthy (Lewis et al. 2006; Umberson 1992). However, the universal protective nature of marriage has been challenged (Carr and Springer 2010). Again, the discussion is hindered by the wide use of cross-sectional designs, which make it impossible to discern to what extent the effects attributed to marriage can also be ascribed to premarital health habits and premarital socioeconomic conditions (Meyler et al. 2007). Individual lives are not unwritten pages at the time of marriage. As outlined in the life-span development principle, conditions earlier in life are crucial to the development of health behavior. Although marital partners are the most important and powerful source of influence in a person's adult life, parents are predominant during childhood (Umberson 1992), and also influence socialization into healthy behaviors (Cardol et al. 2005).

In Missinne et al. (2013), we hypothesized that cumulative life course advantages or disadvantages accumulate at the household level and will be greater than at the individual level. Partners provide each other with information and norms on health behavior (Thomas 2011). Therefore, it can be expected that (un)favorable socioeconomic conditions for either partner in childhood will impact on health behavior in later life. Assortative mating can exacerbate these effects and generate systematic divergences over the life course, as contented by cumulative advantage theory (DiPrete and Eirich 2006). Cultural health capital theory might benefit from the explicit inclusion of the notion of linked lives. To elaborate on how capital is acquired and accumulates over time, it is important to understand the role of the childhood and adult preventive health behaviors of both partners.

The dyadic nature of the SHARE and SHARELIFE enabled scrutinizing the influence of the childhood preventive health care behavior of both wives and husbands on the initiation of mammography screening for a sample of Belgian women $(\mathrm{N}=734)$. Figure 6.3 show the Kaplan-Meier graphs for the married women
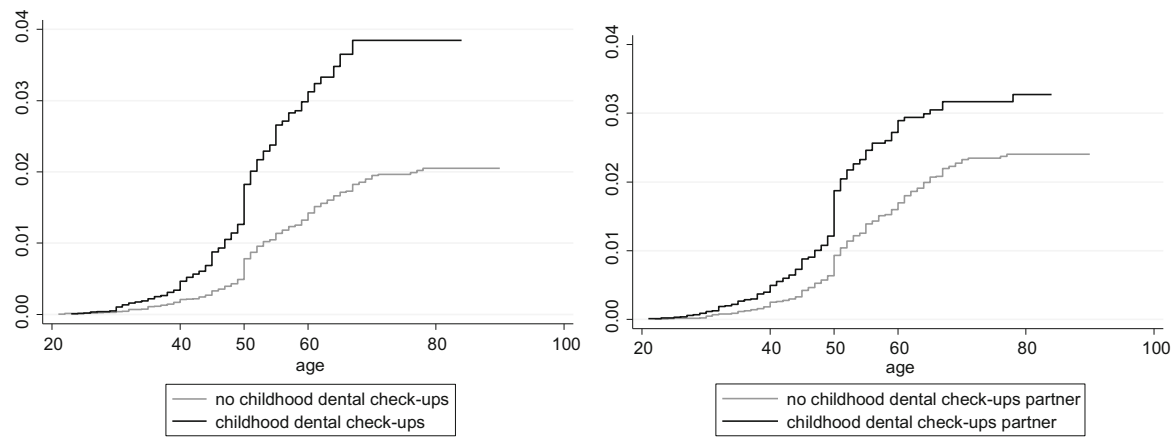

Fig. 6.3 Cumulative hazard functions for the initiation of mammography screening, by childhood dental check-ups of the women and their partners (Nelson-Aalen estimates) 
in our sample. As in Fig. 6.1, childhood preventive behavior seems to impact on mammography screening many years later in life $(\mathrm{p}<0.001)$. However, what is new is the significant effect of the partner's preventive behavior $(\mathrm{p}<0.001)$. Again, the complementary log-log models show that the latter association persists after controlling for the characteristics of the women (number of books during childhood, childhood and lifelong dental check-ups, educational level), the characteristics of the men (childhood and lifelong dental check-ups, educational level), and household wealth. More precisely, the hazard for mammography screening in later life is $25 \%$ higher for women whose husband went regularly for dental check-ups as a child. The results suggest that the cultural health capital of both partners impacts on women's preventive health care use and show the importance of the contextualization of preventive health care use within the family.

\section{Principle 5: Principle of Time and Place}

This principle refers to the fact that the life of every individual is embedded in and shaped by a certain historical context and place (Elder et al. 2003). Historical change can impact on an individual's life. It can also engender cohort effects when it alters the lives of successive birth cohorts, and period effects when the effect is more uniform across these cohorts (Elder 1994). The different aftermath of World War II in Europe than in the United States, illustrates that historical events might impact differently across regions or nations (Elder et al. 2003). To translate this idea into empirical practice, life course researchers urge us to expand the scope from national studies, the results of which can be challenged as being too context specific, into international comparative studies (Billari 2009; Blane et al. 2007). This has now become possible in Europe with the advent of some large-scale research projects that have collected life course data which is fully internationally comparative, such as the SHARE.

Although the cross-national comparative approach is well established in health (e.g. Mackenbach 2012) and health care research (e.g. Devaux 2013), it is still upcoming in preventive health care research (Jusot et al. 2011). However, the existing studies have already revealed substantial cross-national variation in preventive health care habits, including mammography screening (e.g. Wübker 2014). An important question now relates to which institutional differences are the driving forces behind this cross-national variation (Blane et al. 2007). For mammography screening, it seems that general (health care) indicators (such as health care expenditure, number of physicians, and gross domestic product) do not matter (Jusot et al. 2011), but that the country-specific characteristics of mammography screening policies should be focused upon (Wübker 2014).

However, the life course perspective encourages us also to incorporate how these institutional factors change over time and how this can potentially interplay with individual development (Elder et al. 2003, p. 11). During the last few decades, 
European health care systems have been the subject of almost continuous policy reforms. Many of these reforms have been ad hoc interventions aimed at containing rising expenditure on health care (Mossialos 1997). Further, the specific policies on mammography screening have seen a substantial evolution. For example, in Belgium the first initiatives were taken in 1975 (Van Oyen and Verellen 1994), but it was not until 2001 that the national screening program was actually implemented. Countries also differ greatly with regard to this evolution. National coverage had already been achieved in Sweden in 1997 (Schopper and de Wolf 2009), while Poland (Bastos et al. 2010) and Denmark (Schopper and de Wolf 2009) first implemented their national program about a decade later. Cultural health capital theory and health lifestyle theory would benefit from including this notion of time and place. Studying how preventive health care use is affected by the implementations of or changes to policies, might shed light on the strength of the association between cultural health capital and preventive health behavior, as well as on how cultural health capital is acquired and accumulates over time.

In addition to the careful specification of cohort and period effects in the complementary log-log models, I have incorporated this principle more explicitly by combining a cross-national and a longitudinal approach. Figure 6.2 also serves here as an illustration. Figure 6.4 shows the strong variation in the commencement with regular mammography screenings between the 13 European countries that participated in the SHARELIFE. The cumulative hazard is lowest in Denmark and highest in Sweden. It is remarkable that these extremes are both in the Northern European region, which is generally considered as universally the best performing with regard to health, due to relatively generous and universal welfare provision (Mackenbach 2012).

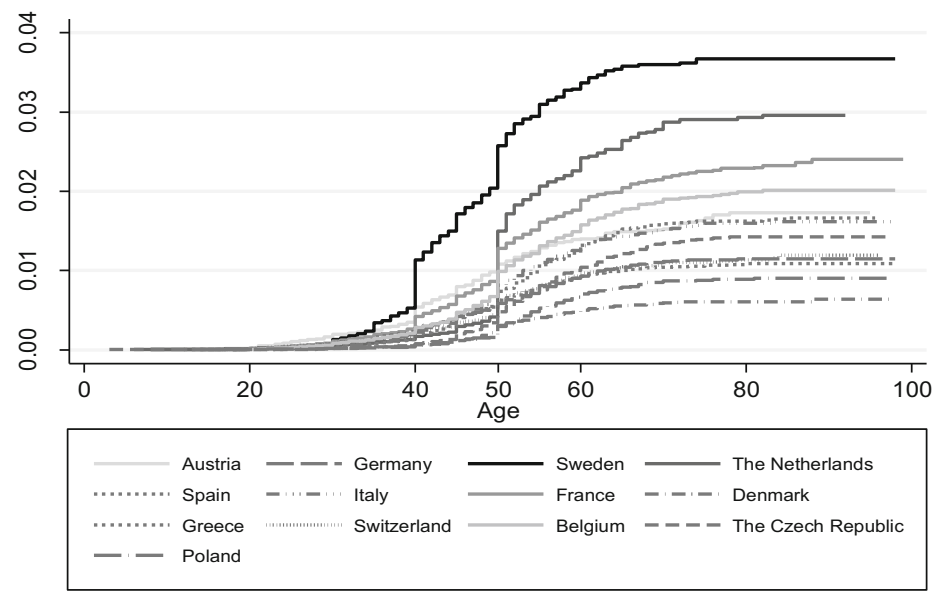

Fig. 6.4 Cumulative hazard function for mammography screening initiation in 13 European countries (Nelson-Aalen estimates) 


\section{Conclusion}

I have argued that a better understanding of the social roots of preventive healthrelated behavior can be gained by combining recent theory formation on preventive health care use with insights from theoretical approaches that have traditionally developed outside the domain of health (care), but which show substantial analogies, specifically here a life course perspective. The example of mammography screening is used to illustrate how each of the five principles of the life course perspective raises new questions that can advance the debate substantially. It is important to note that methodological advancements can also be made. Besides the time-issues discussed in the principle of timing, the longitudinal design allows for the correct time ordering of the conditions. Time ordering is often obscured in health care research, as need for health care is almost always defined by means of questions about prevailing health (at the time of the interview), while items on (preventive) health care use the previous week, month, or year as the time framework. This has hampered conclusions on health care inequalities until now, as research has been predominantly based on cross-sectional designs.

The long-term and developmental perspective of the life course highlights the need to shed further light on which conditions at what life stages contribute to the accumulation of cultural health capital. The results of the first (Missinne et al. 2014) and second study (Missinne et al. 2013) suggest that childhood is a critical period in the development of preventive health behavior. They are in line with a fully path-dependent cumulative advantage process, which implies that the effect of socioeconomic conditions early in life has continuing influences on later life outcomes, even when a person's later socioeconomic position is accounted for (DiPrete and Eirich 2006; Willson et al. 2007). It would be insightful to distinguish further between childhood and adolescence, as well as different periods in adulthood life. Moreover, preventive health care research might benefit from considering the life course perspective's additional focus on the length of exposure (duration) to certain social or health conditions. For example, cumulative exposure models (Willson et al. 2007) propose that effects of social mobility can differ according to the amount of time spent in the different social positions (Bartley and Plewis 2007). Therefore, it would be interesting if surveys could include the age at which individuals moved up or down the social ladder. The notion of timeliness brings about the question of the extent to which age differences in other forms of preventive health are attributable to 'true age effects' or to cohort and period effects, as in the case of mammography screening. In addition to timely initiation, socioeconomic inequality research should move beyond a focus on a snapshot on preventive health behaviors and include their continuous or regular use.

The results also illustrate the importance of contextualizing preventive health care habits within the social network, as suggested by the linked lives principle. They suggest that the cultural health capital of both partners accumulates at the marriage level and impacts on women's preventive health care use. What about other important network members? In older age, friends and offspring are also 
important agents of social control in addition to partners (Lewis and Butterfield 2007). Physicians are also 'significant others' whose roles deserve further attention (Daalman and Elder 2007). Studies have repeatedly shown that even in health care interactions, socioeconomic inequalities exist. For example, it has been reported that more-deprived individuals receive a lower quality of care (Hall and Dornan 1990), spend less time with a doctor (Videau et al. 2010) and receive less information (Willems et al. 2005). Sociological explanations for these divergences are scarce (Willems et al. 2005), but important insights could be derived from the observation that patients in a higher socioeconomic position secure more information from doctors, through effective expressiveness and assertiveness (Verlinde et al. 2012). This active stance precisely constitutes the underlying idea for Shim (2010) developing how cultural health capital may shape the content and tone of patientprovider interactions. The life course perspective highlights that we should extend all these questions beyond the individual level and include the societal processes that shape and reshape the dynamics of inequality that underlie these preventive health care inequalities (Graham 2002). The example of mammography screening illustrates that the role of national policies can be elucidated both by cross-country comparisons and through the study of changes within a single country over time.

A lack of (longitudinal) data and methodological difficulties are only some of the reasons why many of these questions have remained unexplored. At least as important is to keep the underlying theoretical premises in mind. Both life course research and medical sociological theory are particularly well-suited to move beyond the agency-oriented and short-term perspective, which is still dominant in preventive health care research. The life course not only provides a longer-term view and includes the broader societal context, but also stresses that research should be inter-disciplinary, given that inequalities can proliferate across different life domains (Graham 2002).

Open Access This chapter is distributed under the terms of the Creative Commons Attribution Noncommercial License, which permits any noncommercial use, distribution, and reproduction in any medium, provided the original author(s) and source are credited.

\section{References}

Abel, T. (2008). Cultural capital and social inequality in health. Journal of Epidemiology and Community Health, 62, 1-5.

Abel, T., \& Frohlich, K. L. (2012). Capitals and capabilities: Linking structure and agency to reduce health inequalities. Social Science \& Medicine. doi:10.1016/j.socscimed.2011.10.028:236-244.

Andersen, R. M. (1995). Revisiting the behavioral-model and access to medical-care - Does It matter. Journal of Health and Social Behavior, 36, 1-10.

Andersen, R. M., Smedby, B., \& Anderson, O. W. (1970). Medical care use in Sweden and the united states - A comparative analysis of systems and behavior. Chicago: Centre for Health Administration Studies, University of Chicago. 
Bartley, M., \& Plewis, I. (2007). Increasing social mobility: An effective policy to reduce health inequalities. Journal of the Royal Statistical Society Series A-Statistics in Society, 170, 469481.

Bastos, J., Peleteiro, B., Gouveia, J., Coleman, M. P., \& Lunet, N. (2010). The state of the art of cancer control in 30 European countries in 2008. International Journal of Cancer, 126, 27002715.

Becker, M. H., \& Maiman, L. A. (1975). Sociobehavioral determinants of compliance with health and medical care recommendations. Medical Care, 13, 10-24.

Billari, F. C. (2009). The life course is coming of age. Advances in Life Course Research, 14, 83-86.

Blane, D. (1999). The life course, the social gradient and health. In M. Marmot \& R. Wilkinson (Eds.), Social determinants of health (pp. 64-80). Oxford: Oxford University Press.

Blane, D. (2008). Social causes of health and disease. British Journal of Sociology, 59, 588-589.

Blane, D., Netuveli, G., \& Stone, J. (2007). The development of life course epidemiology. Revue D Epidémiologie et de Santé Publique, 55, 31-38.

Bogenhold, D. (2001). Social inequality and the sociology of life style - Material and cultural aspects of social stratification. American Journal of Economics and Sociology, 60, 829-847.

Bourdieu, P. (1984). Distinction - A social critique of the judgement of taste. New York: Routledge.

Bourdieu, P. (1986). The forms of capital. In J. Richardson (Ed.), Handbook of theory and research for the sociology of education (pp. 241-258). New York: Greenwood.

Brandt, M., Deindl, C., \& Hank, K. (2011). Tracing the origins of successful aging: The role of childhood conditions and societal context. MEA discussion paper no. 237-11. Available at SSRN: http://ssrn.com/abstract=1763129

Cardol, M., Groenewegen, P. P., de Bakker, D. H., Spreeuwenberg, P., van Dijk, L., \& van den Bosch, W. (2005). Shared help seeking behaviour within families: A retrospective cohort study. British Medical Journal, 330, 882-884B.

Carr, D., \& Springer, K. W. (2010). Advances in families and health research in the 21 st century. Journal of Marriage and Family, 72, 743-761.

Christakis, N. A., \& Fowler, J. H. (2007). The spread of obesity in a large social network over 32 years. New England Journal of Medicine, 357, 370-379.

Clark, T. N., \& Lipset, S. M. (2001). Are social classes dying? In T. N. Clark \& S. M. Lipset (Eds.), The breakdown of class politics: A debate on post-industrial stratification (pp. 39-54). Baltimore: The Johns Hopkins University Press.

Claussen, B., Smits, J., Naess, O., \& Smith, G. D. (2005). Intragenerational mobility and mortality in Oslo: Social selection versus social causation. Social Science \& Medicine, 61, 2513-2520.

Cockerham, W. C. (2000). The sociology of health behavior and health lifestyles. In C. E. Bird, P. Conrad, \& A. M. Fremont (Eds.), Handbook of medical sociology (pp. 159-172). Upper Saddle River: Prentice-Hall.

Cockerham, W. C. (2005). Health lifestyle theory and the convergence of agency and structure. Journal of Health and Social Behavior, 46, 51-67.

Cockerham, W. C. (2007). Social causes of health and disease. Cambridge: Polity Press.

Daalman, T., \& Elder, G. H. (2007). Family medicine and the life course paradigm. The Journal of the American Board of Family Medicine, 20(1), 85-92.

Daenekindt, S., \& Roose, H. (2013). Cultural chameleons: Social mobility and cultural practices in private and public sphere. Acta Sociologica, 56, 309-324.

Dannefer, D., \& Daub, A. (2009). Extending the interrogation: Life span, life course, and the constitution of human aging. Advances in Life Course Research, 14(1-2), 15-27.

Devaux, M. (2013). Income-related inequalities and inequities in health care services utilisation in 18 selected OECD countries. European Journal of Health Economics.. doi:10.1007/s10198-013-0546-4.

DiPrete, T., \& Eirich, G. (2006). Cumulative advantage as a mechanisms for inequality: A review of theoretical and empirical developments. Annual Review of Sociology, 32, 271-300. 
Donovan, J. E., Jessor, R., \& Costa, F. M. (1993). Structure of health-enhancing behavior in adolescence - A latent-variable approach. Journal of Health and Social Behavior, 34(4), 346362.

Dubbin, L. A., Chang, J. S., \& Shim, J. K. (2013). Cultural health capital and the interactional dynamics of patient-centered care. Social Science \& Medicine, 93, 113-120.

Due, P., Krolner, R., Rasmussen, M., Andersen, A., Damsgaard, M. T., Graham, H., \& Holstein, B. E. (2011). Pathways and mechanisms in adolescence contribute to adult health inequalities. Scandinavian Journal of Public Health, 39, 62-78.

Duport, N., \& Ancelle-Park, R. (2006). Do socio-demographic factors influence mammography use of French women? Analysis of a French cross-sectional survey. European Journal of Cancer Prevention, 15, 219-224.

Elder, G. H. (1974). Children of the great depression: Social change in life experiences. Chicago: University of Chicago Press.

Elder, G. H. (1994). Time, human agency, and social-change - perspectives on the life course. Social Psychology Quarterly, 57, 4-15.

Elder, G. H., Jr. (1998). The life course as developmental theory. Child Development, 69, 1-12.

Elder, G. H., \& Rockwell, R. C. (1979). Life course and human-development - Ecological perspective. International Journal of Behavioral Development, 2, 1-21.

Elder, G. H., Johnson, M. K., \& Crosnoe, R. (2003). The emergence and development of life course theory. In J. T. Mortimer \& M. J. Shanahan (Eds.), Handbook of the life course (pp. 3-19). New York: Kluwer.

Elmore, J. G., Armstrong, K., Lehman, C. D., \& Fletcher, S. W. (2005). Screening for breast cancer. JAMA, 293, 1245-1256.

European Commission. (2003). Council recommendations on cancer screening. http://ec.europa. eu. Accessed 20 May 2012.

Fabri, V., Remacle, A., \& Boutsen, M. (2010). Programme de Dépistage du Cancer du Sein: Comparaison des trois premiers tours 2002-2003, 2004-2005 et 2006-2007 (rapport 7). Bruxelles: Aence Intermualiste (IMA).

Ferlay, J., Parkin, D. M., \& Steliarova-Foucher, E. (2010). Estimates of cancer incidence and mortality in Europe in 2008. European Journal of Cancer, 46, 765-781.

Ferlay, J., Steliarova-Foucher, E., Lortet-Tieulent, J., Rosso, S., Coebergh, J. W., Comber, H., Forman, D., \& Bray, F. (2013). Cancer incidence and mortality patterns in Europe: Estimates for 40 countries in 2012. European Journal of Cancer, 49, 1374-1403.

Fishbein, M., \& Ajzen, I. (1975). Belief, attitude, intervention, and behavior: An introduction to theory and research. Reading: Addison-Wesley.

Fisher, B., Redmond, C. K., \& Fisher, E. R. (2008). Evolution of knowledge related to breast cancer heterogeneity: A 25-year retrospective. Journal of Clinical Oncology, 26(13), 2068-2071.

Frohlich, K. L., Corin, E., \& Potvin, L. (2001). A theoretical proposal for the relationship between context and disease. Sociology of Health \& Illness, 23, 776-797.

Gamoran, A., \& Mare, R. D. (1989). Secondary-school tracking and educational-inequality Compensation, reinforcement, or neutrality. American Journal of Sociology, 94, 1146-1183.

Gangl, M. (2004). Welfare states and the scar effects of unemployment: A comparative analysis of the United States and West Germany. American Journal of Sociology, 109, 1319-1364.

George, L. K. (1993). Sociological perspectives on life transitions. Annual Review of Sociology, $19,353-373$.

Glenn, N. D. (1976). Cohort analysts futile quest - Statistical attempts to separate age, period and cohort effects. American Sociological Review, 41, 900-904.

Glenn, N. D. (2003). Distinguishing age, period, and cohort effects. In J. T. Mortimer \& M. J. Shanahan (Eds.), Handbook of the life course (pp. 465-476). New York: Kluwer Academic/Plenum Publishers.

Gotzsche, P. C., \& Nielsen, M. (2009). Screening for breast cancer with mammography. Cochrane Database of Systematic Reviews, 4, Artn Cd001877.

Graham, H. (2002). Building an inter-disciplinary science of health inequalities: The example of lifecourse research. Social Science \& Medicine, 55, 2005-2016. 
Hakama, M., Coleman, M. P., Alexe, D. M., \& Auvinen, A. (2008). Cancer screening: Evidence and practice in Europe 2008. European Journal of Cancer, 44, 1404-1413.

Halfon, N., \& Hochstein, M. (2002). Life course health development: An integrated framework for developing health, policy, and research. Milbank $Q, 80,433-479$. iii.

Hall, J. A., \& Dornan, M. C. (1990). Patient sociodemographic characteristics as predictors of satisfaction with medical-care - A meta-analysis. Social Science \& Medicine, 30, 811-818.

Hayward, M. D., \& Gorman, B. K. (2004). The long arm of childhood: The influence of early-life social conditions on men's mortality. Demography, 41, 87-107.

Heinz, W. R., \& Krüger, H. (2001). Life course: Innovations and challenges for social research. Current Sociology, 49(2), 29-45.

Jemal, A. (2011). Global cancer statistics. CA: A Cancer Journal for Clinicians, 61, 69-90.

Jepson, R., Clegg, A., Forbes, C., Lewis, R., Snowden, A., \& Kleijnen, J. (2000). The determinants of screening uptake and interventions for increasing uptake: A systematic review. Health Technology Assessment, 4, 1-133.

Jusot, J. F., Or, Z., \& Sirven, N. (2011). Variations in preventive care utilisation in Europe. European Journal of Ageing. doi:10.1007/s10433-011-0211-7.

Karvonen, S., Rimpela, A. H., \& Rimpela, M. K. (1999). Social mobility and health related behaviours in young people. Journal of Epidemiology and Community Health, 53, 211-217.

Kuh, D., Ben-Shlomo, Y., Lynch, J., Hallqvist, J., \& Power, C. (2003). Life course epidemiology. Journal of Epidemiology and Community Health, 57(10), 778-783.

Kuh, D., Power, C., Blane, D., \& Bartley, M. (2004). Socioeconomic pathways between childhood and adult health. In D. Kuh \& Y. Ben Shlomo (Eds.), A life course approach to chronic disease epidemiology (pp. 371-395). Oxford: Oxford University Press.

Lau, R. R., Quadrel, M. J., \& Hartman, K. A. (1990). Development and change of young-adults preventive health beliefs and behavior - Influence from parents and peers. Journal of Health and Social Behavior, 31, 240-259.

Lewis, M. A., \& Butterfield, R. M. (2007). Social control in marital relationships: Effect of one's partner on health behaviors. Journal of Applied Social Psychology, 37(2), 298-319.

Lewis, M. A., McBride, C. M., Pollak, K. I., Puleo, E., Butterfield, R. M., \& Emmons, K. M. (2006). Understanding health behavior change among couples: An interdependence and communal coping approach. Social Science \& Medicine, 62, 1369-1380.

Mackenbach, J. P. (2012). The persistence of health inequalities in modern welfare states: The explanation of a paradox. Social Science \& Medicine, 75, 761-769.

Meyler, D., Stimpson, J. P., \& Peek, M. K. (2007). Health concordance within couples: A systematic review. Social Science \& Medicine, 64, 2297-2310.

Mirowsky, J., \& Ross, C. E. (2003). Education, social status, and health. New York: de Gruyter, Inc.

Missinne, S., \& Bracke, P. (2014). Age differences in mammography screening reconsidered: Life course trajectories in 13 European countries. European Journal of Public Health. doi:10.1093/eurpub/cku077.

Missinne, S., Colman, E., \& Bracke, P. (2013). Spousal influence on mammography screening: A life course perspective. Social Science \& Medicine, 98, 63-70.

Missinne, S., Neels, K., \& Bracke, P. (2014). Reconsidering inequalities in preventive health care: An application of cultural health capital theory and the life course perspective. Sociology of Health \& Illness, 36(8), 1259-1275.

Monden, C. W., \& de Graaf, N. D. (2012). The importance of father's and own education for self-assessed health across Europe: An east-west divide? Sociology of Health \& Illness, 35, 977-992.

Mossialos, E. (1997). Citizens' views on health care systems in the 15 member states of the European Union. Health Economics, 6, 109-116.

Newman, J. F., \& Gift, H. C. (1992). Regular pattern of preventive dental services - A measure of access. Social Science and Medicine, 35, 997-1001.

Pescosolido, B. A. (1992). Beyond rational choice - The social dynamics of how people seek help. American Journal of Sociology, 97, 1096-1138. 
Phelan, J. C., Link, B. G., Diez-Roux, A., Kawachi, I., \& Levin, B. (2004). "Fundamental causes" of social inequalities in mortality: A test of the theory. Journal of Health and Social Behavior, 45, 265-285.

Rajaram, S. S., \& Rashidi, A. (1998). Minority women and breast cancer screening: The role of cultural explanatory models. Preventive Medicine, 27, 757-764.

Riley, P., Worthington, H. V., Clarkson, J. E., \& Beirne, P. V. (2013). Recall intervals for oral health in primary care patients (review). The Cochrane Library. doi:10.1002/14651858.

Ryder, N. B. (1965). The cohort as a concept in the study of social-change. American Sociological Review, 30, 843-861.

Schafer, M. H., Ferraro, K. F., \& Mustillo, S. A. (2011). Children of misfortune: Early adversity and cumulative inequality in perceived life trajectories. American Journal of Sociology, 116, 1053-1091.

Schopper, D., \& de Wolf, C. (2009). How effective are breast cancer screening programmes by mammography? Review of the current evidence. European Journal of Cancer, 45, 1916-1923.

Schutz, G., Ursprung, H. W., \& Wossmann, L. (2008). Education policy and equality of opportunity. Kyklos, 61, 279-308.

Shim, J. K. (2010). Cultural health capital: A theoretical approach to understanding health care interactions and the dynamics of unequal treatment. Journal of Health and Social Behavior, 51, $1-15$.

Singh-Manoux, A., \& Marmot, M. (2005). Role of socialization in explaining social inequalities in health. Social Science \& Medicine, 60, 2129-2133.

Spadea, T., Bellini, S., Kunst, A., Stirbu, I., \& Costa, G. (2010). The impact of interventions to improve attendance in female cancer screening among lower socioeconomic groups: A review. Preventive Medicine, 50, 159-164.

Stirbu, I., Kunst, A., Mielck, A., \& Mackenbach, J. P. (2007). Educational inequalities in utilization of preventive services among elderly in Europe. Rotterdam: Department of Public Health.

Thomas, P. A. (2011). Trajectories of social engagement and limitations in late life. Journal of Health and Social Behavior, 52, 430-443.

Tinsley, B. J., Markey, C. N., Ericksen, A. J., Ortiz, R. V., \& Kwasman, A. (2002). Health promotion for parents. In M. H. Bornstein (Ed.), Handbook of parenting: Practical issues in parenting (Vol. 5, pp. 311-328). London: Lawrence Erlbaum Associates.

Umberson, D. (1992). Gender, marital-status and the social-control of health behavior. Social Science \& Medicine, 34, 907-917.

Umberson, D., Crosnoe, R., \& Reczek, C. (2010). Social relationships and health behavior across the life course. Annual Review of Sociology, 36(36), 139-157.

Van der Heyden, J. H. A., Demarest, S., Tafforeau, J., \& Van Oyen, H. (2003). Socio-economic differences in the utilisation of health services in Belgium. Health Policy, 65, 153-165.

van Doorslaer, E., Masseria, C., \& Koolman, X. (2006). Inequalities in access to medical care by income in developed countries. Canadian Medical Association Journal, 174, 177-183.

Van Oyen, H., \& Verellen, W. (1994). Breast cancer screening in the Flemish region, Belgium. European Journal of Cancer Prevention, 3, 7-12.

Verlinde, E., Delaender, N., DeMaesschalck, S., Deveugele, M., \& Willems, S. (2012). The social gradient in doctor-patient communication. International Journal of Equity in Health, 11, 12.

Videau, Y., Saliba-Serre, B., Paraponaris, A., \& Ventelou, B. (2010). Why patients of low socioeconomic status with mental health problems have shorter consultations with general practitioners. Journal of Health Services Research \& Policy, 15(2), 76-81.

von Karsa, L., Anttila, A., Ronco, G., Ponti, A., Malila, N., Arbyn, M., et al. (2008). Cancer Screening in the European Union. Report on the implementation of the Council Recommendation on cancer screening. Luxembourg: European Communities.

Weber, M. (1922/1978). Economy and society (Vol. 1). Berkeley, California: University of California Press.

WHO. (2013). Breast cancer: Prevention and control. http://www.who.int/cancer/detection/ breastcancer/en/. Accessed 8 Sept 2013. 
Wickrama, K. A. S., Conger, R. D., Wallace, L. E., \& Elder, G. H. (1999). The intergenerational transmission of health-risk behaviors: Adolescent lifestyles and gender moderating effects. Journal of Health and Social Behavior, 40(3), 258-272.

Willems, S., De Maesschalck, S., Deveugele, M., Derese, A., \& De Maeseneer, J. (2005). Socioeconomic status of the patient and doctor-patient communication: Does it make a difference? Patient Education and Counseling, 56, 139-146.

Williams, S. J. (1995). Theorizing class, health and life-styles - Can Bourdieu help Us. Sociology of Health \& Illness, 17(5), 577-604.

Willson, A. E., Shuey, K. M., \& Elder, G. H. (2007). Cumulative advantage processes as mechanisms of inequality in life course health. American Journal of Sociology, 112, 18861924.

Wu, L. L. (2003). Event history models for life course analysis. In J. T. Mortimer \& M. J. Shanahan (Eds.), Handbook of the life course (pp. 477-502). New York: Kluwer.

Wübker, A. (2012). Who gets a mammogram amongst European women aged 50-69 years? Health Economics Review, 2, 1-13.

Wübker, A. (2014). Explaining variations in breast cancer screening across European countries. The European Journal of Health Economics, 15(5), 497-514.

Youlden, D. R., Cramb, S. M., Dunn, N. A., Muller, J. M., Pyke, C. M., \& Baade, P. D. (2012). The descriptive epidemiology of female breast cancer: An international comparison of screening, incidence, survival and mortality. Cancer Epidemiology, 36, 237-248. 